\title{
Phasic Alterations in Dopamine and Serotonin Release in Striatum and Prefrontal Cortex in Response to Cocaine Predictive Cues in Behaving Rhesus Macaques
}

\author{
Charles W Bradberry*,' and Susan R Rubino \\ 'Department of Psychiatry and the center for the Neural Basis of Cognition, University of Pittsburg, PA, USA; ${ }^{2}$ Department of Neurology, Yale \\ University and VA, West Haven, CT, USA
}

\begin{abstract}
The ability of environmental cues associated with cocaine availability to cause relapse may result from conditioned activation of dopamine (DA) release. We examined this hypothesis in macaque monkeys by conducting microdialysis studies in animals during exposure to a cocaine predictive compound cue. In addition to studying DA release in mesolimbic and sensorimotor striatum, both DA and serotonin levels were determined in the prefrontal cortex (medial orbitofrontal and anterior cingulate). The compound cue employed visual, auditory, and olfactory components, and was salient to the animals as demonstrated by anticipatory lever pressing in the absence of cocaine. During a 10-min period of exposure prior to cocaine availability, there was no significant increase in striatal or cortical DA. The addition of a DA uptake inhibitor to the striatal perfusate to reduce the potential interference of neuronal uptake did not alter the results. In contrast to the lack of any change in striatal DA, a significant decrease in extracellular serotonin in the prefrontal cortex during the 10 min of cue exposure was observed.

Neuropsychopharmacology (2004) 29, 676-685, advance online publication, 28 January 2004; doi: I 0. I 038/sj.npp. 1300386
\end{abstract}

Keywords: cingulate; orbitofrontal; cocaine; dopamine; self-administration; serotonin; primate

\section{INTRODUCTION}

Cues associated with the availability of drugs such as cocaine are believed to increase the risk for relapse during abstinence (Bouton and Swartzentruber, 1991; Childress et al, 1992; Crombag and Shaham, 2002). The present study was designed to investigate phasic neurotransmitter alterations associated with exposure of rhesus monkeys to cocaine-associated cues. The objectives were to determine the dopaminergic effects in mesolimbic striatum, sensorimotor striatum, and prefrontal cortex, and the serotonergic effects in the prefrontal cortex. Microdialysis methods were employed to monitor extracellular neurotransmitter levels. Animals were in a drug-free state during exposure to cues, after which the direct effects of self-administered cocaine were determined.

As an unconditioned stimulus, intravenous cocaine causes increased extracellular dopamine (DA) and serotonin due to blockade of the respective neuronal transporters (Bradberry and Roth, 1989; Bradberry et al, 1993). A

* Correspondence: CW Bradberry, 3025 E. Carson St., Pittsburgh, PA |5203, USA, Tel: + | 412-483-709|, Fax: + | 412-483-6799,

E-mail: bradberrycw@upmc.edu

Received 07 October 2003; revised 04 December 2003; accepted 07 December 2003

Online publication: 18 December 2003 at http://www.acnp.org/ citations/Npp | 2 18030346 |/default.pdf conditioned increase in DA neurotransmission by cocaineassociated cues has been predicted (Spanagel and Weiss, 1999; Robinson and Berridge, 2000), based upon patterns of DA neuronal responses to nondrug rewards (Schultz, 1998) and progressive effects associated with chronic cocaine exposure (Robinson and Berridge, 2000). In relapse models, there are similar effects of drug-associated cues, priming injections of cocaine, and stressors known to activate DA neurotransmission (Shalev et al, 2002). However, there are conflicting reports in the literature on the ability of conditioned and discriminative cues to increase DA release (Brown and Fibiger, 1992; Fontana et al, 1993; Neisewander et al, 1996; Ito et al, 2000, 2002; Weiss et al, 2000).

Serotonin (5-HT) is implicated in the regulation of affect and impulsivity (Lucki, 1998; Higley and Bennett, 1999). Its release is activated by environmental stimuli such as stressors (Chaouloff, 2000), and there is evidence of its involvement in the incentive value of cocaine cues (Harris et al, 2001). However, a direct role for 5-HT, in particular cortical 5-HT, in cocaine cue effects has not described.

In human brain imaging studies, phasic alterations in the frontal cortex and ventral striatal function upon exposure to environmental or internal imagery cues associated with the use of cocaine have been demonstrated (Breiter et al, 1997; Garavan et al, 2000; Kilts et al, 2001), with correlations between frontal cortex metabolism and self-reports of craving (Grant et al, 1996; Maas et al, 1998; Childress et al, 
1999; Wang et al, 1999). The orbitofrontal and anterior cingulate cortex are the regions most consistently activated in these studies.

We have previously reported that in rhesus monkeys, cocaine cue exposure did not result in any conditioned increase in extracellular DA (Bradberry et al, 2000). However, in those studies animals were always receiving cocaine at some point in the session, except in a few specific instances in which either saline or no cue exposure at all was presented. Thus, the most significant predictive cues could have been the experience of being placed in a behavior chair in the self-administration chamber rather than the specific cues signaling cocaine's immediate availability. To address this possibility, the present studies employed a discriminative stimulus (DS) \pm approach in which specific compound cues were presented after microdialysis measurements had begun, indicating either impending cocaine or impending saline availability following a $10-\mathrm{min}$ interval. This made all handling prior to presentation of the compound stimulus of no predictive value with respect to cocaine availability, and provided a drug-free 10-min period in which to monitor the neurochemical response to the DS. The DS was left on during the remainder of the session, and cocaine or saline availability was signaled by a common discrete cue, making the DS a contextual cue as well as a DS. We believe that this combination of discriminative and contextual cues is a valid naturalistic model of human drug use, in that there are particular contexts that are both predictive of cocaine consumption, and in which cocaine continues to be used during a particular session.

A specific hypothesis that cues would result in increased extracellular DA in the ventral striatum and prefrontal cortex was examined. We did not have a specific prediction as to the effects of cues on extracellular 5-HT in the prefrontal cortex because there is no extensive literature base associating phasic changes in neuronal activity to appetitive cues as is the case with DA.

\section{MATERIALS AND METHODS}

Sessions were conducted according to alternating weeks of daily conditioning and no conditioning. During the 'no conditioning' week, animals remained in their home cage. The rationale for this was one of maximizing the chronic intermittent effects of cocaine. Sensitization, a model of increasing incentive salience of cocaine and its associated cues (Robinson and Berridge, 1993, 2000), has been shown in previous studies to be most robust under conditions of intermittent administration (Kalivas and Stewart, 1991; Robinson et al, 1998; Vanderschuren and Kalivas, 2000). During the active week, animals were conditioned daily according to a pseudorandom schedule with slightly more DS + cocaine sessions than DS - saline sessions.

\section{Compound Stimuli}

Compound stimuli were used because of evidence that they exert greater control over behavior, and thus produce more robust conditioning than single modality cues (Panlilio et al, 1996, 1998; See et al, 1999). The compound stimulus we employed was a combination of a visual cue, an auditory cue, and an olfactory cue. The visual component of the compound cue was the onset of a single red or green lamp placed on either side of a vertically oriented pair of red and green lamps in the middle of the operant panel in front of the animal. The vertical and horizontal distance between the lamps was $10.3 \mathrm{~cm}$. The auditory cue was an ascending or descending series of tones, beginning at $1000 \mathrm{~Hz}$, and making four transitions of $50 \mathrm{~Hz}$ steps at $200 \mathrm{~ms}$ intervals prior to returning to $1000 \mathrm{~Hz}$, continually repeating. Prior to the tones, white noise was present. The olfactory cue was one of two odorants introduced into the chamber through a sidewall in a stream of air that had bubbled through a solution of the odorant in ethylene glycol. Two $28 \mathrm{~V}$ valves on each chamber were controlled by the Med-Associates interface panel, enabling the selection of odor to present upon compound stimulus onset. The presence of the odor was obvious within seconds because of the proximity to the animal of the sidewall through which the air stream passed. The odorants were either cineole (eucalyptus) or amyl acetate (reminiscent of banana scent). These two odorants have been used in the past for characterizing neuronal responses to odor cues in macaque monkeys (Rolls et al, 1996). The sets of cues were presented to them in a counterbalanced manner such that the set of cues representing cocaine and saline were reversed for two of the four animals. For example, the DS + cocaine cue for one pair of animals was red light, ascending tones, cineole odor; the DS - saline cue was green light, descending tones, amyl acetate odor. The DS + and DS- were reversed for the other pair of animals.

At $10 \mathrm{~min}$ after DS presentation, cocaine self-administration began. An initial $0.5 \mathrm{mg} / \mathrm{kg}$ infusion was made available, indicated by a discrete visual cue separate from the compound stimulus under an FR30 response contingency. The discrete cue was the onset of the vertical pair of lamps on the operant panel, and was the same cue for both cocaine and saline. The use of a common discrete visual cue indicating impending saline or cocaine makes the DS condition a contextual cue, or 'occasion setter' that gives meaning to the discrete cue (Crombag et al, 2000). This initial infusion was followed by a 20 -min timeout, after which up to five additional $0.5 \mathrm{mg} / \mathrm{kg}$ infusions were available (FR30) with a 10-min timeout between each infusion. The vertical pair of lamps serving as the discrete cue was off during the timeout, and then came back on to signal the end of the timeout. Responding during the timeout period had no consequence. Figure 1 shows a diagram of this conditioning/self-administration protocol. The horizontal arrow indicates the progression through a session, which includes the neutral precue period, the cued, predrug expectancy period, and the period during which cocaine (or saline) was available for self-administration.

\section{Animals}

Studies were conducted in four rhesus monkeys not previously used for behavioral/drug self-administration studies. Two female and two male animals were used. Following habituation to handling and placement in a Primate Products restraint chair, animals were trained to respond for food pellets in the same Med-associates operant 
Presentation of compound cue specific for cocaine or saline

Cocaine $(0.5 \mathrm{mg} / \mathrm{kg})$ or saline availability signaled by a common discrete visual cue

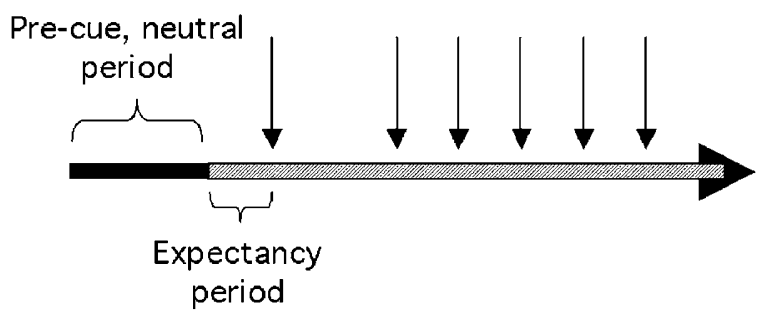

Figure I Diagram of conditioning protocol. Precue neutral period in the behavioral chamber lasts approximately $60 \mathrm{~min}$ before the presentation of compound discriminative/contextual cue. The expectancy period between cue onset and availability of the first cocaine infusion is $10 \mathrm{~min}$. The same discrete cue signals immediate availability under FR30 contingency of both cocaine (DS + condition) and saline (DS - condition).

chamber used for the cocaine conditioning and selfadministration procedures. For food pellet reinforcement, an FR 30 contingency was employed, with food pellet availability signaled by the vertical pair of lamps that served as the discrete cue in the cocaine conditioning studies. Prior to beginning microdialysis studies, animals were exposed to cocaine and the associated DS + cues in order to acquaint them with the drug effects and the associated cues. There were six to nine sessions (mean $7.8 \pm 0.8$ for the four animals). The unit dose of cocaine during these familiarizing sessions was $0.1 \mathrm{mg} / \mathrm{kg}$, lower than the $0.5 \mathrm{mg} / \mathrm{kg}$ dose used during the microdialysis studies. The mean cumulative cocaine intake over the course of the familiarization sessions was $2.8 \pm 0.6 \mathrm{mg} / \mathrm{kg}$.

\section{Microdialysis}

Two dialysis studies were conducted during each active week of conditioning, one on Tuesday (probe placed on Monday), and one on Friday (probe placed on Thursday). A constraint was imposed such that DS + dialysis studies had to occur at least $48 \mathrm{~h}$ after the last cocaine exposure to avoid any concerns about acute tolerance (Bradberry, 2000). DSstudies could occur $24 \mathrm{~h}$ after the last cocaine exposure. Microdialysis studies were conducted essentially as previously described in greater detail (Bradberry et al, 2000). In brief, animals had bilateral chronic guide cannulae, consisting of an open well base (constructed from polysulfone rather than Delrin as previously), onto which a $16 \times 6$ grid could be placed with the spacing of holes at $1 \mathrm{~mm}$. Acrylic covers were screwed onto the bases when studies were not being conducted. For placement of microdialysis probes, a thin piece of plastic was placed between the open well and the grid that was penetrated only where a probe was to be placed, thus maintaining an effective aseptic barrier. Ethylene oxide sterilized probes were placed the day prior to the study, and protected upon return to the home cage by a plastic cap that was bolted in place on the animal's implant. The following day, the cap was removed, the animal was placed in the behavioral chamber, and inlet and outlet lines were attached to the microdialysis probes.

Two probes could be placed for each study, with one in the cortex and the other in the striatum, and were placed in tissue not previously penetrated. There were usually two studies per active week (active and inactive weeks alternated). The placement of probes was unilateral, alternating between brain hemispheres. Placement sites were calculated based upon postsurgical MR imaging. Striatal assignments were designated ventromedial, central, or dorsolateral based upon the descriptions of Haber et al (1995) and Haber et al (2000), and would correspond functionally to mesolimbic, associational, and sensorimotor placements. Cortical placements were in either anterior cingulate or medial orbitofrontal cortex. Striatal probes all had a $4 \mathrm{~mm}$ exposed length of dialysis tubing. Cortical probes ranged in length of exposed tubing from 3 to $6 \mathrm{~mm}$.

In a selected number of studies in two of the four animals, $5 \mu \mathrm{M}$ nomifensine was added to the perfusate in order to reduce DA uptake in the immediate vicinity of the dialysis probe. This was carried out to reduce the potential that neuronal uptake was preventing an increase in DA release at nerve terminals from being reflected as increased extracellular DA in the larger extracellular compartment sampled by the microdialysis probe. We have previously characterized the concentration of nomifensine in microdialysis studies in awake animals (Adams et al, 2002).

The solution used to perfuse the probe at a flow rate of $5.0 \mu \mathrm{l} / \mathrm{min}$ was (in $\mathrm{mM}$ ): $\mathrm{KCl} 2.4, \mathrm{NaCl} 137, \mathrm{CaCl}_{2} 1.2, \mathrm{MgCl}_{2}$ 1.2, $\mathrm{NaH}_{2} \mathrm{PO}_{4} 0.9 ; \mathrm{pH}$ 7.4. DA and 5-HT in the perfusate were determined using liquid chromatography with electrochemical detection. An Antec-Leyden (Zoeterwoude, The Netherlands) Intro potentiostat and detector cell assembly was used in conjunction with $15 \mathrm{~cm} \times 2.1 \mathrm{~mm}$ or $3.0 \mathrm{~mm}$ ID columns with a BDS Hypersil C18 material (Keystone Scientific). An ESA (Chelmsford, MA) model 465 autosampler or LC Packings (Amsterdam, The Netherlands) Famos autosampler was used for injection of samples. Samples were stabilized by the addition of acetic acid to prevent DA degradation while in the autosampler, which was maintained at $4{ }^{\circ} \mathrm{C}$. The 2 -min samples (total 10 and $6.4 \mu \mathrm{l}$ injected) were collected for striatal DA determinations, while 10-min samples (total 50 and $40 \mu l$ injected) were collected for cortical DA and 5-HT determinations. Both monoamines from the cortex were determined in the same run. The mobile phase for all determinations was (in $\mathrm{mM}$ ): $\mathrm{Na}_{2} \mathrm{HPO}_{4}, 0.05$; EDTA, 0.1 ; sodium octylsulfonate 1.25. A measure of $130 \mathrm{ml}$ methanol was added per liter final volume, and $\mathrm{pH}$ was unadjusted.

\section{Data Analysis}

To determine if there were changes in extracellular neurotransmitter levels associated with the presentation of the DS, two-way repeated measures ANOVA was employed, with DS condition as the between factor. This analysis was across all four animals, as each was exposed to both DS conditions, and each probe insertion (always in previously unpenetrated tissue) was treated as an independent experimental unit. For the repeated measures ANOVA, neurotransmitter levels were converted to a \% baseline, defined as 
the mean of the three points just prior to cue presentation. Basal neurotransmitter levels reported are the dialysate levels, uncorrected for probe recovery. For analysis of the effect of the DS condition on behavioral responding at different periods, multifactorial ANOVA was conducted, with DS condition as a factor. Multifactorial ANOVA was also used to determine the effect of nomifensine on basal DA levels in striatal subregions.

For the prefrontal cortex, the results from probe placements in both the orbitofrontal and cingulate cortex were pooled. This decision was made based upon the similarity in response of these regions to cocaine cues in human imaging studies (see Introduction).

\section{RESULTS}

\section{Behavioral Responding}

The effectiveness of the DS \pm conditioning paradigm (Figure 2) was demonstrated by evaluating lever press responses prior to cocaine self-administration. There was no significant difference in the rate of responding between the DS + and DS - sessions before the DS presentation, indicating equivalence between the two conditions before the cue. After presentation of the DS, but before the discrete cue signaling immediate cocaine or saline availability, there was a greater than four-fold increase in responding in the DS + condition relative to the DS- condition $\left(\mathrm{F}_{(1,161)}=17.3, p<0.0001\right)$, indicating that there was salience of the DS + cue to the animal (Figure 2). Upon presentation of the discrete cue, responding was also significantly greater for cocaine $(0.77 \pm 0.07 \mathrm{Resp} / \mathrm{s})$ than saline $\left(0.38 \pm 0.05 \mathrm{Resp} / \mathrm{s}, \mathrm{F}_{(1,161)}=17.2, p<0.0001\right)$.

\section{Time Course of Contingency Learning}

The work of Schultz and co-workers (Schultz, 1998; Tremblay et al, 1998; Schultz and Dickinson, 2000) has highlighted the important role of DA neuronal activation during contingency learning or when the outcome is not certain (Fiorillo et al, 2003). The studies reported herein

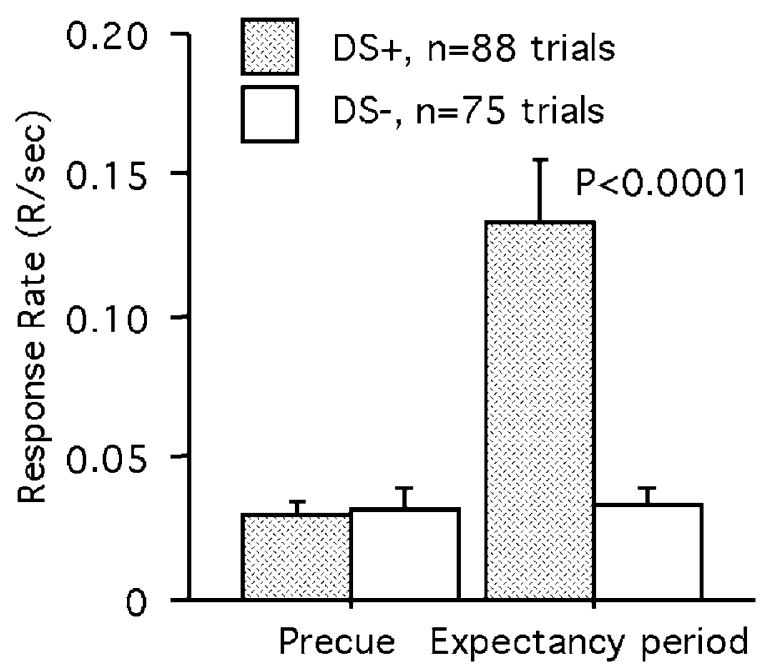

Figure 2 Behavioral responding during the indicated times in the protocol in Figure I. Trials are averaged over all four animals. were conducted following a small (6-9) number of sessions in which the DS + cues were paired with subsequent cocaine availability at a reduced unit dose $(0.1$ vs $0.5 \mathrm{mg} /$ $\mathrm{kg}$ ). Thus, the vast majority of the total number of cocaine sessions of the animals and total cumulative cocaine exposure occurred during the course of the microdialysis studies. It is not possible to define a discrete point at which contingency learning has occurred, and presumably, there is a gradual strengthening over time of the association between the predictive cues and subsequent cocaine or saline. However, to determine if there were significant differences in responding early on in the course of conditioning, the first eight cocaine and saline conditioning sessions after microdialysis had begun were examined. At that fairly early window in the entire course of studies, there were significant differences in anticipatory responding in response to the DS presentation (DS $+: 0.137 \pm 0.037 \mathrm{Resp} / \mathrm{s}$; DS-: $\left.0.056 \pm 0.014 \mathrm{Resp} / \mathrm{s} ; t_{(62)}=2.004, p<0.05\right)$. However, there were no significant differences in responding to the discrete cue (DS + : 0.705 \pm 0.129 ; DS-: $0.612 \pm 0.088$, NS). Thus, it would appear that while there was some understanding of the predictive significance of the DS + , the DS was not fully functional as an occasion setter during the early part of the studies, and that learning of the significance of the different cues was ongoing during the course of the studies.

\section{Extracellular DA in Striatum}

A summary of the anatomical placements for striatal microdialysis probes is presented in Figure 3. These placements are based upon the predicted trajectories from the postsurgical MR images. We typically found that at least four sections at $1 \mathrm{~mm}$ intervals corresponded to the three sections at $1 \mathrm{~mm}$ intervals in the atlas (Martin and Bowden, 2000) from which these sections were adapted.

The effect of cue presentation followed by cocaine or saline on extracellular striatal DA is indicated in Figure 4a, with the results collapsed across all animals and striatal subregions, and on a scale that encompasses the pharmacological impact of the self-administered cocaine. There is a significant difference $\left(\mathrm{F}_{(19,1292)}=32.6 ; p<0.0001\right)$ by twoway repeated measures ANOVA) between the two conditions due to the effect of cocaine in the DS + condition as compared to saline in the DS - condition. Figure $4 \mathrm{~b}$ shows a restricted time course encompassing only the cue presentation, and at an expanded scale on the ordinate. When analyzed over the period of time shown in Figure $4 \mathrm{~b}$, which does not include the effect of cocaine, there is no significant difference between the two conditions $\left(\mathrm{F}_{(9,612)}=0.557\right.$; NS).

Figure 5 presents the results of cue and cocaine presentation on striatal DA, broken down by striatal subregion. Figure $5 \mathrm{a}$ shows the effects of cue and subsequent cocaine for the ventromedial, central, and dorsolateral striatum. In each region, there was a highly significant difference between the DS + and DS - condition due to the cocaine (ventromedial: $\mathrm{F}_{(19,228)}=5.8, p<0.0001$; central: $\mathrm{F}_{(19,741)}=32.1, p<0.0001$; dorsolateral: $\mathrm{F}_{(19,247)}=$ $15.8, p<0.0001)$. In Figure $5 \mathrm{~b}$, the data analysis is limited to the $10 \mathrm{~min}$ prior to, and $10 \mathrm{~min}$ postcue (but before cocaine). As can be seen, there is no significant impact of 


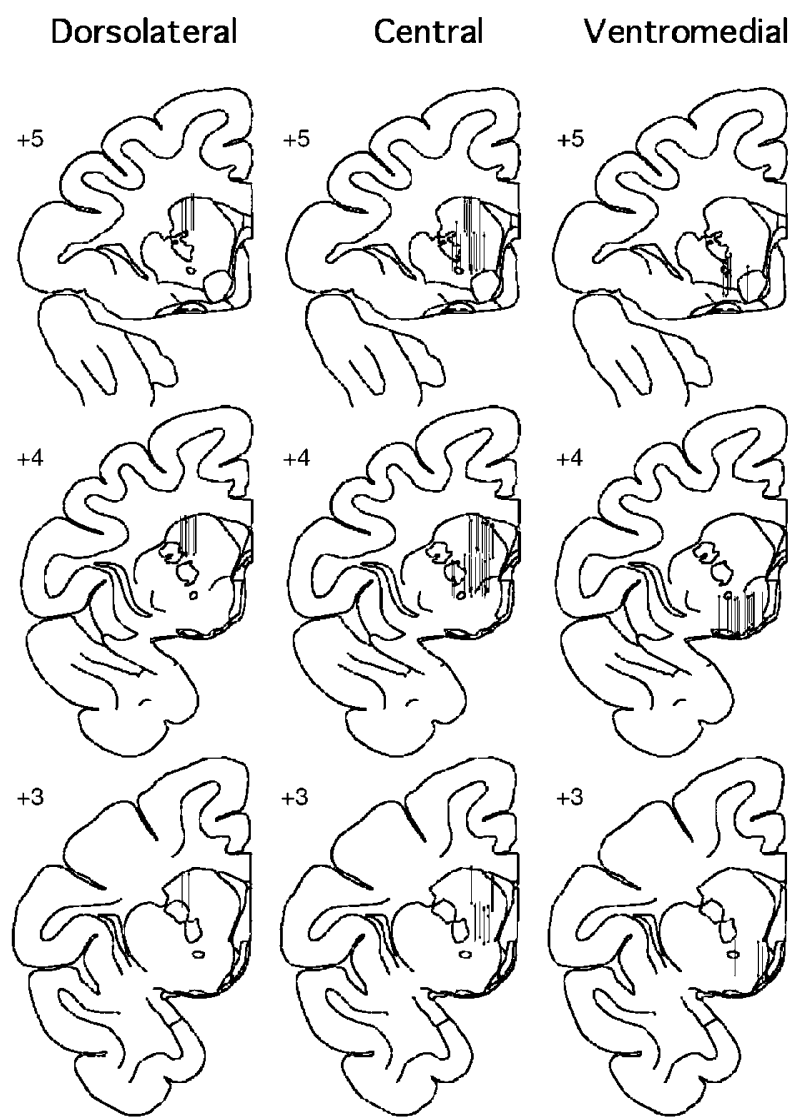

Figure 3 Representation of sites of striatal microdialysis probe placement. Sections are adapted from the atlas of Martin and Bowden (2000). Placements are in ventromedial, central, or dorsolateral striatum. The numbers on sections refer to distance from the anterior commissure.

the cue alone in any region (ventromedial: $\mathrm{F}_{(9,108)}=0.84$; central: $\mathrm{F}_{(9,351)}=0.66$; dorsolateral: $\mathrm{F}_{(9,117)}=1.68$; all NS).

A concern related to observing a lack of activation of DA release was the possibility that active neuronal uptake was preventing an increased release from reaching the extracellular compartment sampled by the microdialysis probe. To determine if that was the case, experiments were conducted in two of the four animals in which the DA uptake inhibitor nomifensine was added to the perfusate at a concentration of $5 \mu \mathrm{M}$. Studies were only conducted with central and ventromedial placements, and only with the DS + condition. As an indication that there was effective local inhibition of DA uptake, the mean absolute levels of DA in the dialysate were higher in the presence of nomifensine (central striatum: $7.2 \pm 1.2(n=5)$ vs $4.0 \pm 0.3$ $(n=42), \quad \mathrm{F}_{(1,45)}=9.2, \quad p<0.005$; ventromedial striatum: $6.4 \pm 1.2(n=7)$ vs $\left.2.5 \pm 0.4(n=14), \mathrm{F}_{(1,19)}=14.5, p<0.005\right)$

Figure 6 presents the results of cue presentation and cocaine self-administration on extracellular DA in the presence of nomifensine. Figures $6 \mathrm{a}$ and $\mathrm{b}$ encompass the cue and cocaine effect for the ventromedial and central regions, resp. Note the very much smaller effect of the selfadministered cocaine, due to the pre-existing partial uptake inhibition resulting from local nomifensine. Figure $6 \mathrm{c}$ presents the data limited to the immediate pre- and postcue periods. In neither the ventromedial $\left(\mathrm{F}_{(9,54)}=1.17, \mathrm{NS}\right)$ nor central placements $\left(\mathrm{F}_{(9,36)}=0.89, \mathrm{NS}\right)$ was there a significant
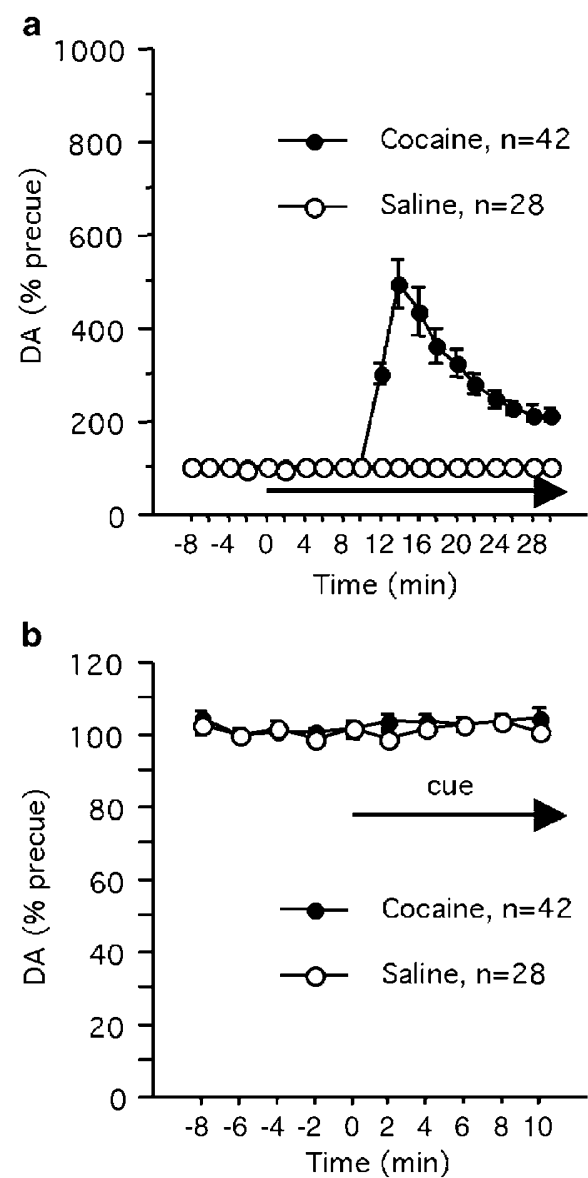

Figure 4 (a) Dialysate levels of DA collapsed across all striatal subregions during cue exposure and subsequent cocaine or saline infusion. At time $=0$, cue onset begins. (b) Dialysate DA from all striatal subregions on an expanded scale, encompassing only the 10 min prior and 10 min post cue onset. No significant cue effect.

effect of cue onset as determined by one-way repeated measures ANOVA.

\section{Extracellular DA and 5-HT in the Prefrontal Cortex}

In addition to studying the striatal DA response to the DS presentation, we also examined the cortical DA and 5-HT response. Figure 7 indicates the microdialysis placements for the studies. As can be seen, the sites incorporated both anterior cingulate and medial orbitofrontal regions. Samples were analyzed for both DA and 5-HT, although both neurotransmitters were not always measurable in each placement. Figure 8 presents the effect of the cue and cocaine on cortical DA. Given the much lower basal values of cortical DA, it was necessary to employ 10-min sampling intervals. Basal values did not differ between conditions (DS + condition, $0.206 \pm 0.031 \mathrm{fmol} / \mu \mathrm{l}, n=22$; DS - condition, $0.133 \pm 0.021 \mathrm{fmol} / \mu \mathrm{l}, n=11 ; t_{(31)}=1.59$, NS). As with striatal DA, there was no significant effect of the cue on extracellular DA $\left(\mathrm{F}_{(3,93)}=0.35, \mathrm{NS}\right)$, as determined by two-way repeated measures ANOVA over the four time points prior to cocaine self-administration at $t=10 \mathrm{~min}$. The expected effect of self-administered cocaine is highly significant $\left(\mathrm{F}_{(5,155)}=7.92 ; p<0.001\right)$, as can be seen when analyzing the entire data set shown in the figure. 

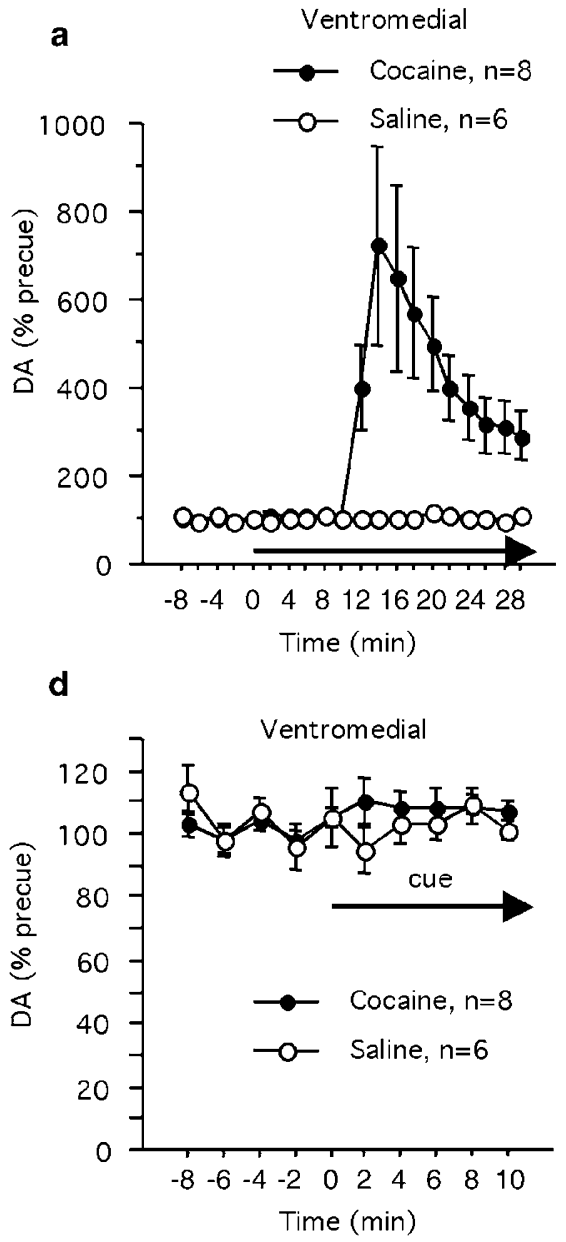

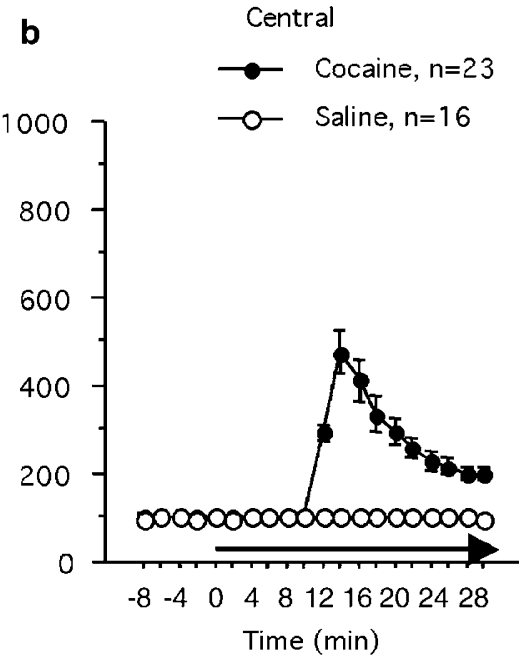

e

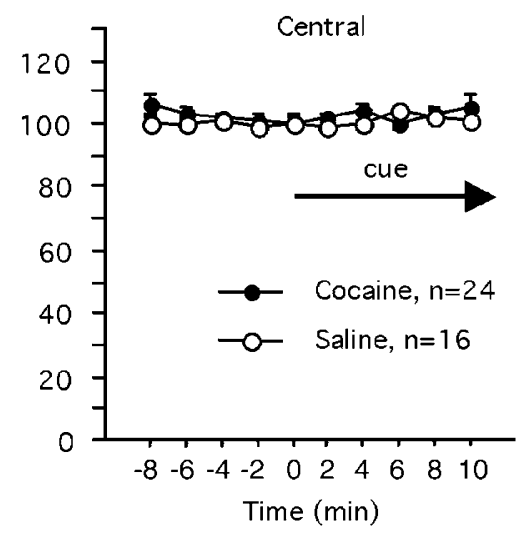

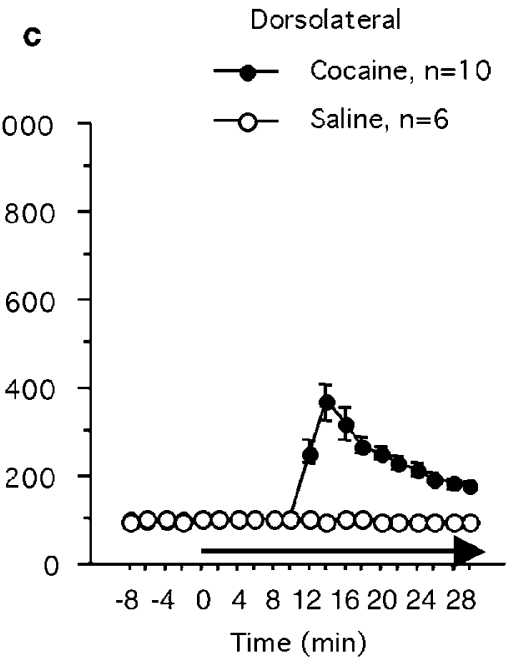

$\mathbf{f}$

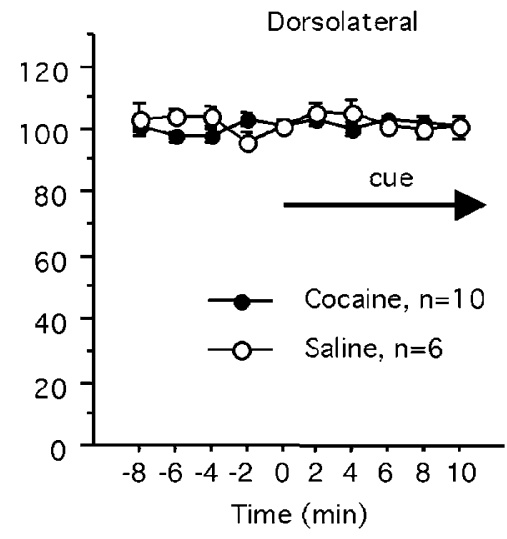

Figure $5(a-c)$ Dialysate levels of DA in each striatal subregion during cue exposure and subsequent cocaine or saline infusion. ( $d-f$ ) Dialysate DA levels in each striatal subregion on an expanded scale, encompassing only the 10 min prior and 10 min postcue onset. No significant cue effect in any region.

In Figure 9, the effects of the cue and cocaine on extracellular 5-HT is presented. Again, due to very low basal levels of 5 -HT, the sampling periods were $10 \mathrm{~min}$. Basal values did not differ between conditions (DS + condition, $0.219 \pm 0.068 \mathrm{fmol} / \mu \mathrm{l}, n=11$; DS - condition, $0.161 \pm$ $\left.0.038 \mathrm{fmol} / \mu \mathrm{l}, n=9 ; t_{(18)}=0.72, \mathrm{NS}\right)$. Here, the presentation of the DS + resulted in a significant decrease in cortical 5-HT. When analyzed over the four data points shown prior to cocaine self-administration, by one-way repeated measures ANOVA, there is a significant change over time in the cocaine group $\left(\mathrm{F}_{(3,30)}=5.27, p<0.005\right)$ but not in the saline group $\left(\mathrm{F}_{(3,24)}=0.75, \mathrm{NS}\right)$. There is also a significant difference between the two conditions by two-way repeated measures ANOVA $\left(\mathrm{F}_{(3,54)}=3.17, p<0.05\right)$, with the time point at $t=10$ different between the two conditions $\left(t_{(18)}=2.75, p<0.02\right)$. When analyzed over the entire time course in Figure 9, there is a highly significant difference between the two conditions $\left(\mathrm{F}_{(5,85)}=3.75 ; p<0.01\right)$ due to the effect of cocaine.

\section{DISCUSSION}

Our results demonstrate that a combined discriminative/ contextual cue associated with cocaine availability produces a phasic decrease in extracellular 5-HT in the prefrontal cortex of primates. In contrast, there are no significant cueassociated changes in DA release in either the striatum or the prefrontal cortex.

There is an increasing awareness that addiction is associated with prefrontal cortex dysfunction (Porrino and Lyons, 2000; Goldstein and Volkow, 2002), and that the effects of cocaine cues are mediated in large part by altered cortical activity (Grant et al, 1996; Maas et al, 1998; Childress et al, 1999; Garavan et al, 2000; Kilts et al, 2001; Wexler et al, 2001). This contrasts with the greater focus in the rodent literature on subcortical mechanisms of cue effects. In primates, there is a prominent role of the anterior cingulate and orbitofrontal cortex in action initiation (and inhibition) and reward evaluation (Rolls, 1996; Bush et al, 2002; Shidara and Richmond, 2002). Anterior cingulate cortex has the highest density of 5-HT innervation in humans (Mantere et al, 2002). 5-HT is considered to be involved in behavioral inhibition, satiety, control of affect (Lucki, 1998), and in contextual cue conditioning (Wilkinson et al, 1995). It is possible that the phasic reduction in 5-HT we observed is secondary to the activation of the prefrontal cortex consistently observed in imaging studies in response to cocaine-associated cues or imagery (Grant et al, 1996; Maas et al, 1998; Childress et al, 1999; Wang et al, 1999; Garavan et al, 2000; Kilts et al, 2001; Wexler et al, 


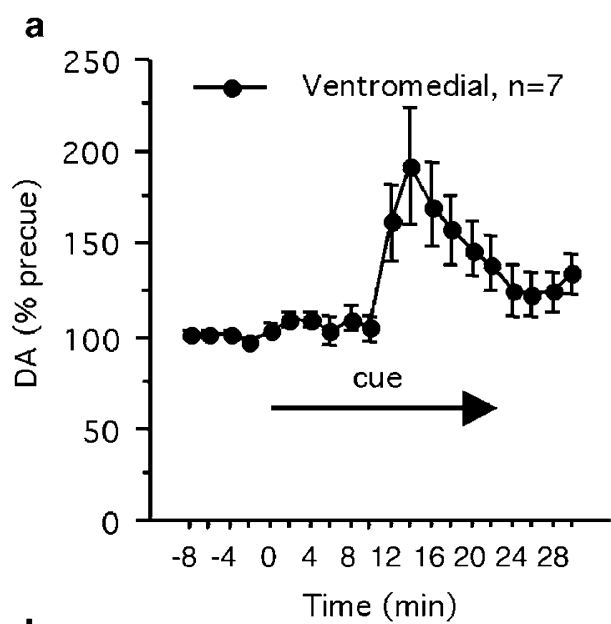

b

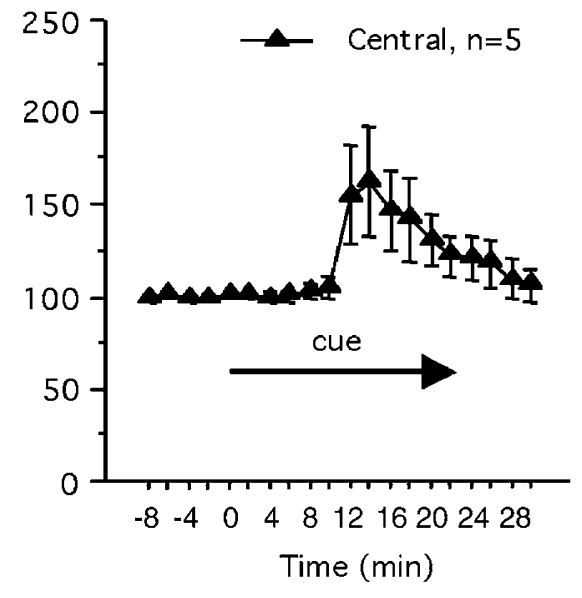

C

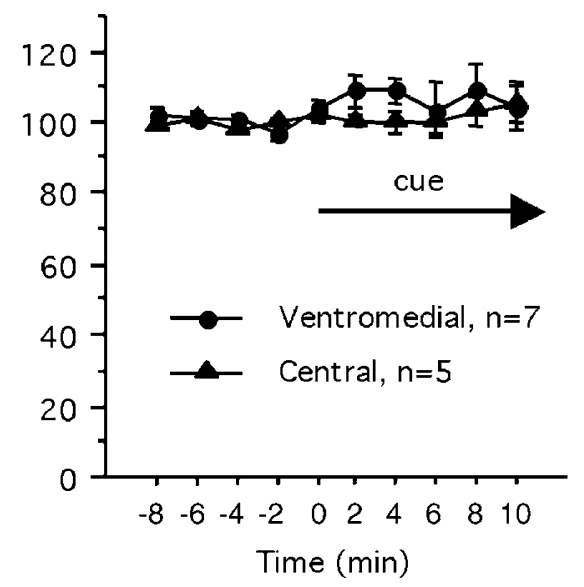

Figure 6 Impact of DS + cue exposure and cocaine while infusing a DA uptake blocker ( $5 \mu \mathrm{M}$ nomifensine) through the dialysis probe. $(\mathrm{a}, \mathrm{b})$ : Dialsyate DA from ventromedial and central striatum showing a diminished impact of cocaine. (c): Dialysate DA levels in each striatal subregion on an expanded scale, encompassing only the 10 min prior and 10 min postcue onset. No significant cue effect in either region.

2001). There is a direct projection from the prefrontal cortex to the dorsal raphe (Arnsten and Goldman-Rakic, 1984; Sesack et al, 1989; Buchanan et al, 1994; Hajos et al, 1998; Chiba et al, 2001), which appears to be a glutamatergic input to GABAergic neurons in the raphe (Varga et al, 2001). The activation of the prefrontal cortex results in

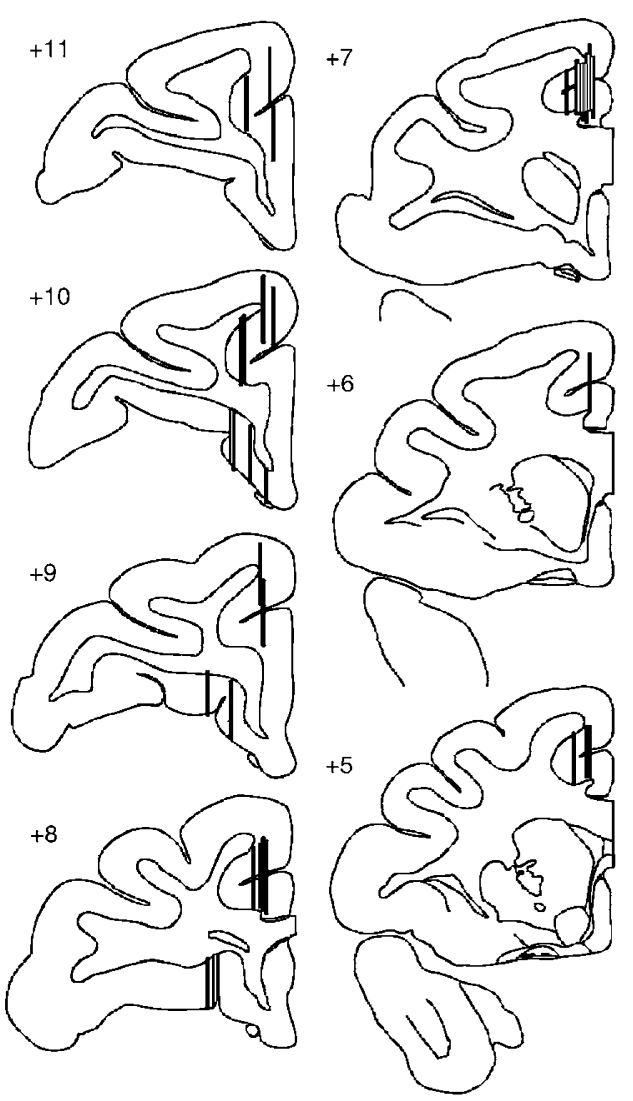

Figure 7 Representation of sites of cortical microdialysis probe placement. Sections are adapted from the atlas of Martin and Bowden (2000). Placements are in the anterior cingulate and medial orbitofrontal cortex. The numbers on sections refer to distance from the anterior commissure.

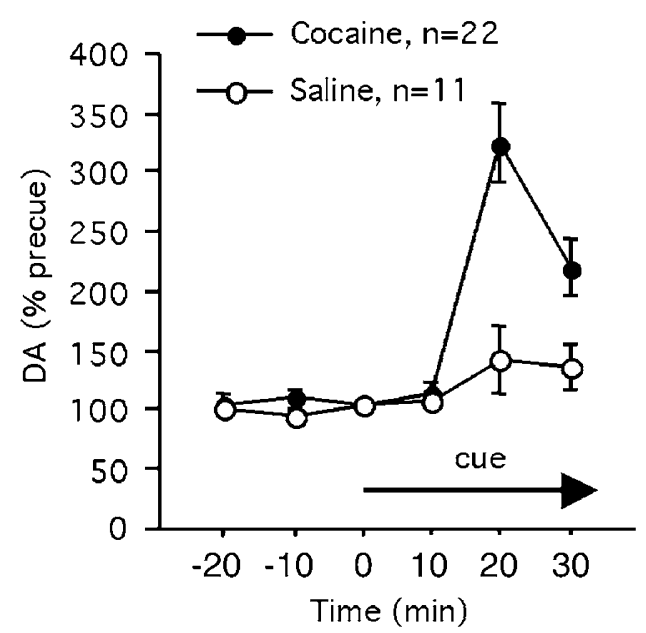

Figure 8 Dialysate levels of DA in the prefrontal cortex during cue exposure and subsequent cocaine or saline. Time point at $t=10$ represents the sample collected during cue exposure, and $t=20$ the first postcocaine time point. There was no significant effect of the cue.

diminished 5-HT neuronal firing via that long-loop feedback (Hajos et al, 1998, 1999; Celada et al, 2001; Varga et al, 2001). Thus, as cortical activity increases upon exposure to drug cues, activation of inhibitory interneurons in the raphe could be diminishing serotonergic output. 


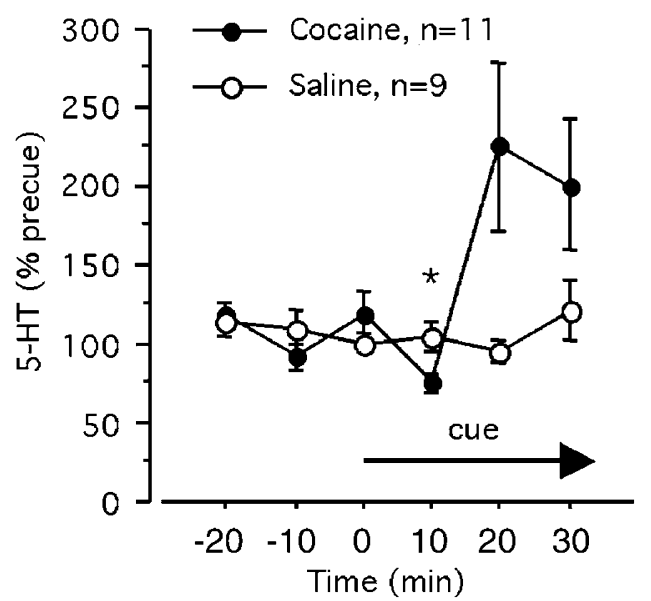

Figure 9 Dialysate levels of $5-\mathrm{HT}$ in the prefrontal cortex during cue exposure and subsequent cocaine or saline. Time point at $t=10$ represents the sample collected during cue exposure, and $t=20$ the first postcocaine time point. By two-way repeated ANOVA, there was a significant difference over the time from $t=-20$ to 10 , with post hoc analysis indicating that the time point at $t=10$ was significantly reduced in the DS + condition $(* p<0.02)$

While the trait of reduced 5-HT function is associated with impulsivity, and increased preference for ethanol in humans as well as non-human primates (Higley and Bennett, 1999), phasic changes in 5-HT release are also behaviorally important. For example, increases in 5-HT neurotransmission can decrease the incentive value of cocaine-associated environments (Harris et al, 2001), and intraraphe infusion of a $5-\mathrm{HT}_{1 \mathrm{~A}}$ agonist (which decreases 5-HT terminal release) reinstated ethanol self-administration in a relapse model (Le et al, 2002). Reductions in cortical 5-HT release (van Erp and Miczek, 2000) have been observed during bouts of aggression. While preparation for, and engagement in, aggression is different from preparation for cocaine self-administration, there may be a common link of anticipation and preparation to engage in a behavior with affective significance. Given the common link of reduced 5-HT function with preference for another abused drug (ethanol) and impulsivity in primates, and the prominent consideration of impulsivity in substance dependence (Jentsch and Taylor, 1999; Volkow and Fowler, 2000; Goldstein and Volkow, 2002), our observation of phasic reductions in 5-HT release suggests a potential role for 5-HT enhancers in an effort to reduce relapse, as has been suggested by others (Rothman et al, 2002).

In the rodent, some (Ito et al, 2000, 2002; Weiss et al, 2000), but not all (Brown and Fibiger, 1992; Neisewander et al, 1996) studies have observed that there are sustained increases in DA in striatal subregions depending on the nature of the cocaine-associated cues, contingencies of their presentation, and particular subregion examined. For example, Ito et al (2000) observed that noncontingent presentation of a cocaine-associated visual stimulus evoked an increased release of DA in the nucleus accumbens core, whereas contingent presentation of the stimulus was able to activate DA release in the dorsal striatum (Ito et al, 2002). Weiss et al (2000) observed that presentation of a DS along with a discrete stimulus caused an increase in extracellular DA in the nucleus accumbens and a resumption of responding after an extended period of extinction. In contrast, we did not observe significant changes in extracellular striatal DA even in the presence of local uptake inhibition, which would decrease the effect of uptake to contain changes in DA release within the synapse.

There have also been studies indicating that discriminative stimuli predictive of cocaine are able to activate prefrontal cortex Fos protein in rats in a DA-dependent manner (Ciccocioppo et al, 2001), but no direct measurements of DA have been reported in the literature. In the primate prefrontal cortex, where $\mathrm{D}_{1}$-like receptors predominate over $\mathrm{D}_{2}$, an extrasynaptic localization is most often observed (Smiley et al, 1994), and there is very sparse DA uptake in the prefrontal cortex (Sesack et al, 1998), consistent with volume transmission mediation of DA actions. This suggests that if cortical DA release increased during cue exposure, it should have been detected in the extrasynaptic compartment sampled by the microdialysis probe. The elegant electrophysiological work of Schultz and co-workers (Schultz, 1998) using cues signaling nondrug rewards in monkeys has been central to the growing focus on phasic DA responses in the ability of cues to control drug-seeking behavior. However, those electrophysiological responses in the non-human primate are brief, subsecond phenomena, and rapid time course voltametric measurements have confirmed the very brief activation of extracellular DA by cocaine-associated cues (Phillips et al, 2003). Our results indicate that there is no enduring alteration in DA release in response to cocaine cues that could be mediating an enduring state of anticipation or concerted action to seek out cocaine.

In conclusion, we have demonstrated phasic reductions in cortical 5-HT release during cocaine predictive cues, suggesting a potential role for phasic reductions in cortical 5-HT in cue-induced drug seeking. In addition, the present results question, at least in the primate, the involvement of cortical or striatal DA in cocaine cue effects.

\section{ACKNOWLEDGEMENTS}

The support of this work by DA 10331 and the Yale VA Center on Alcoholism is gratefully acknowledged, as is the technical assistance of Cynthia Santaniello, Jennifer Probert, Dinh TP Le, Shawna Ellis, and Steve Logsdon.

\section{REFERENCES}

Adams BW, Bradberry CW, Moghaddam B (2002). NMDA antagonist effects on striatal dopamine release: microdialysis studies in awake monkeys. Synapse 43: 12-18.

Arnsten AF, Goldman-Rakic PS (1984). Selective prefrontal cortical projections to the region of the locus coeruleus and raphe nuclei in the rhesus monkey. Brain Res 306: 9-18.

Bouton ME, Swartzentruber D (1991). Sources of relapse after extinction in Pavlovian and Instrumental Learning. Clin Psychol Rev 11: 123-140.

Bradberry CW (2000). Acute and chronic dopamine dynamics in a nonhuman primate model of recreational cocaine use. J Neurosci 20: 7109-7115.

Bradberry CW, Barrett-Larimore RL, Jatlow P, Rubino SR (2000). Impact of self-administered cocaine and cocaine cues on extracellular dopamine in mesolimbic and sensorimotor striatum in rhesus monkeys. J Neurosci 20: 3874-3883. 
Bradberry CW, Nobiletti JB, Elsworth JD, Murphy B, Jatlow P, Roth RH (1993). Cocaine and cocaethylene: microdialysis comparison of brain drug levels and effects on dopamine and serotonin. J Neurochem 60: 1429-1435.

Bradberry CW, Roth RH (1989). Cocaine increases extracellular dopamine in rat nucleus accumbens and ventral tegmental area as shown by in vivo microdialysis. Neurosci Lett 103: 97-102.

Breiter HC, Gollub RL, Weisskoff RM, Kennedy DN, Makris N, Berke JD et al (1997). Acute effects of cocaine on human brain activity and emotion. Neuron 19: 591-611.

Brown EE, Fibiger HC (1992). Cocaine-induced conditioned locomotion: absence of associated increases in dopamine release. Neuroscience 48: 621-629.

Buchanan SL, Thompson RH, Maxwell BL, Powell DA (1994). Efferent connections of the medial prefrontal cortex in the rabbit. Exp Brain Res 100: 469-483.

Bush G, Vogt BA, Holmes J, Dale AM, Greve D, Jenike MA et al (2002). Dorsal anterior cingulate cortex: a role in reward-based decision making. Proc Natl Acad Sci USA 99: 523-528.

Celada P, Puig MV, Casanovas JM, Guillazo G, Artigas F (2001). Control of dorsal raphe serotonergic neurons by the medial prefrontal cortex: involvement of serotonin-1A, GABA(A), and glutamate receptors. J Neurosci 21: 9917-9929.

Chaouloff F (2000). Serotonin, stress and corticoids (comment). J Psychopharmacol 14: 139-151.

Chiba T, Kayahara T, Nakano K (2001). Efferent projections of infralimbic and prelimbic areas of the medial prefrontal cortex in the Japanese monkey, Macaca fuscata. Brain Res 888: 83-101.

Childress AR, Ehrman R, Rohsenow DJ, Robbins SJ, O’Brien CP (1992). Classically conditioned factors in drug dependence. In: Lowinson JW, Luiz P, Millman RB, Langard G (eds). Substance Abuse: A Comprehensive Textbook. Williams \& Wilkins: Baltimore.

Childress AR, Mozley PD, McElgin W, Fitzgerald J, Reivich M, O'Brien CP (1999). Limbic activation during cue-induced cocaine craving. Am J Psychiatry 156: 11-18.

Ciccocioppo R, Sanna PP, Weiss F (2001). Cocaine-predictive stimulus induces drug-seeking behavior and neural activation in limbic brain regions after multiple months of abstinence: reversal by $\mathrm{D}(1)$ antagonists. Proc Natl Acad Sci USA 98: 19761981.

Crombag HS, Badiani A, Maren S, Robinson TE (2000). The role of contextual versus discrete drug-associated cues in promoting the induction of psychomotor sensitization to intravenous amphetamine. Behav Brain Res 116: 1-22.

Crombag HS, Shaham Y (2002). Renewal of drug seeking by contextual cues after prolonged extinction in rats. Behav Neurosci 116: 169-173.

Fiorillo CD, Tobler PN, Schultz W (2003). Discrete coding of reward probability and uncertainty by dopamine neurons. Science 299: 1898-1902.

Fontana DJ, Post RM, Pert A (1993). Conditioned increases in mesolimbic dopamine overflow by stimuli associated with cocaine. Brain Res 629: 31-39.

Garavan H, Pankiewicz J, Bloom A, Cho JK, Sperry L, Ross TJ et al (2000). Cue-induced cocaine craving: neuroanatomical specificity for drug users and drug stimuli. Am J Psychiatry 157: 1789-1798.

Goldstein RZ, Volkow ND (2002). Drug addiction and its underlying neurobiological basis: neuroimaging evidence for the involvement of the frontal cortex [review]. Am J Psychiatry 159: $1642-1652$

Grant S, London ED, Newlin DB, Villemagne VL, Liu X, Contoreggi $C$ et al (1996). Activation of memory circuits during cue-elicited cocaine craving. Proc Natl Acad Sci USA 93: 12040-12045.

Haber SN, Fudge JL, McFarland NR (2000). Striatonigrostriatal pathways in primates form an ascending spiral from the shell to the dorsolateral striatum. J Neurosci 20: 2369-2382.
Haber SN, Kunishio K, Mizobuchi M, Lyndbalta E (1995). The orbital and medial prefrontal circuit through the primate basal ganglia. J Neurosci 15: 4851-4867.

Hajos M, Hajos-Korcsok E, Sharp T (1999). Role of the medial prefrontal cortex in 5-HT1A receptor-induced inhibition of 5-HT neuronal activity in the rat. $\mathrm{Br} J$ Pharmacol 126: $1741-1750$.

Hajos M, Richards CD, Szekely AD, Sharp T (1998). An electrophysiological and neuroanatomical study of the medial prefrontal cortical projection to the midbrain raphe nuclei in the rat. Neuroscience 87: 95-108.

Harris GC, Altomare K, Aston-Jones G (2001). Preference for a cocaine-associated environment is attenuated by augmented accumbal serotonin in cocaine withdrawn rats. Psychopharmacologia 156: 14-22.

Higley JD, Bennett AJ (1999). Central nervous system serotonin and personality as variables contributing to excessive alcohol consumption in non-human primates. (Review) (152 refs). Alcohol Alcoholism 34: 402-418.

Ito R, Dalley JW, Howes SR, Robbins TW, Everitt BJ (2000). Dissociation in conditioned dopamine release in the nucleus accumbens core and shell in response to cocaine cues and during cocaine-seeking behavior in rats. J Neurosci (Online) 20 7489-7495.

Ito R, Dalley JW, Robbins TW, Everitt BJ (2002). Dopamine release in the dorsal striatum during cocaine-seeking behavior under the control of a drug-associated cue. J Neurosci 22: 6247-6253.

Jentsch JD, Taylor JR (1999). Impulsivity resulting from frontostriatal dysfunction in drug abuse: implications for the control of behavior by reward-related stimuli (review) (240 refs). Psychopharmacology 146: 373-390.

Kalivas PW, Stewart J (1991). Dopamine transmission in the initiation and expression of drug- and stress-induced sensitization of motor activity (review). Brain Res Brain Res Rev 16: 223-244.

Kilts CD, Schweitzer JB, Quinn CK, Gross RE, Faber TL, Muhammad F et al (2001). Neural activity related to drug craving in cocaine addiction. Arch Gen Psychiatry 58: 334-341.

Le AD, Harding S, Juzytsch W, Fletcher PJ, Shaham Y (2002). The role of corticotropin-releasing factor in the median raphe nucleus in relapse to alcohol. J Neurosci 22: 7844-7849.

Lucki I (1998). The spectrum of behaviors influenced by serotonin. Biol Psychiatry 44: 151-162.

Maas LC, Lukas SE, Kaufman MJ, Weiss RD, Daniels SL, Rogers VW et al (1998). Functional magnetic resonance imaging of human brain activation during cue-induced cocaine craving. $A m$ J Psychiatry 155: 124-126.

Mantere T, Tupala E, Hall H, Sarkioja T, Rasanen P, Bergstrom K et al (2002). Serotonin transporter distribution and density in the cerebral cortex of alcoholic and nonalcoholic comparison subjects: a whole-hemisphere autoradiography study. $A m \mathrm{~J}$ Psychiatry 159: 599-606.

Martin RF, Bowden DM (2000). Primate Brain Maps: Structure of the Macaque Brain. Elsevier: Amsterdam.

Neisewander JL, O'Dell LE, Tran-Nguyen LT, Castaneda E, Fuchs RA (1996). Dopamine overflow in the nucleus accumbens during extinction and reinstatement of cocaine self-administration behavior. Neuropsychopharmacology 15: 506-514.

Panlilio LV, Weiss SJ, Schindler CW (1996). Cocaine selfadministration increased by compounding discriminative stimuli. Psychopharmacology 125: 202-208.

Panlilio LV, Weiss SJ, Schindler CW (1998). Motivational effects of compounding discriminative stimuli associated with food and cocaine. Psychopharmacology 136: 70-74.

Phillips PEM, Stuber GD, Heien M, Wightman RM, Carelli RM (2003). Subsecond dopamine release promotes cocaine seeking. Nature 422: 614-618. 
Porrino LJ, Lyons D (2000). Orbital and medial prefrontal cortex and psychostimulant abuse: studies in animal models. Cereb Cortex 10: 326-333.

Robinson TE, Berridge KC (1993). The neural basis of drug craving: an incentive-sensitization theory of addiction (review). Brain Res Brain Res Rev 18: 247-291.

Robinson TE, Berridge KC (2000). The psychology and neurobiology of addiction: an incentive-sensitization view (review) (217 refs). Addiction 95: S91-S117.

Robinson TE, Browman KE, Crombag HS, Badiani A (1998). Modulation of the induction or expression of psychostimulant sensitization by the circumstances surrounding drug administration. Neurosci Biobehav Rev 22: 347-354.

Rolls ET (1996). The orbitofrontal cortex (review) (103 refs). Philos Trans Roy Soc Lond B Biol Sci 351: 1433-1443.

Rolls ET, Critchley HD, Mason R, Wakeman EA (1996). Orbitofrontal cortex neurons: role in olfactory and visual association learning. J Neurophysiol 75: 1970-1981.

Rothman RB, Blough BE, Baumann MH (2002). Appetite suppressants as agonist substitution therapies for stimulant dependence. Ann N Y Acad Sciences 965: 109-126.

Schultz W (1998). Predictive reward signal of dopamine neurons (review) (302 refs). J Neurophysiol 80: 1-27.

Schultz W, Dickinson A (2000). Neuronal coding of prediction errors (review) (112 refs). Annu Rev Neurosci 23: 473-500.

See RE, Grimm JW, Kruzich PJ, Rustay N (1999). The importance of a compound stimulus in conditioned drug-seeking behavior following one week of extinction from self-administered cocaine in rats. Drug Alcohol Depend 57: 41-49.

Sesack SR, Deutch AY, Roth RH, Bunney BS (1989). Topographical organization of the efferent projections of the medial prefrontal cortex in the rat: an anterograde tract-tracing study with Phaseolus vulgaris leucoagglutinin. J Comp Neurol 290: 213-242.

Sesack SR, Hawrylak VA, Matus C, Guido MA, Levey AI (1998). Dopamine axon varicosities in the prelimbic division of the rat prefrontal cortex exhibit sparse immunoreactivity for the dopamine transporter. J Neurosci 18: 2697-2708.

Shalev U, Grimm JW, Shaham Y (2002). Neurobiology of relapse to heroin and cocaine seeking: a review. Pharmacol Rev 54: 1-42.

Shidara M, Richmond BJ (2002). Anterior cingulate: single neuronal signals related to degree of reward expectancy (comment). Science 296: 1709-1711.
Smiley JF, Levey AI, Ciliax BJ, Goldman-Rakic PS (1994). D1 dopamine receptor immunoreactivity in human and monkey cerebral cortex: predominant and extrasynaptic localization in dendritic spines. Proc Natl Acad Sci USA 91: 5720-5724.

Spanagel R, Weiss F (1999). The dopamine hypothesis of reward: past and current status (Review) (67 refs). Trends Neurosci 22: 521-527.

Tremblay L, Hollerman JR, Schultz W (1998). Modifications of reward expectation-related neuronal activity during learning in primate striatum. J Neurophysiol 80: 964-977.

Vanderschuren LJ, Kalivas PW (2000). Alterations in dopaminergic and glutamatergic transmission in the induction and expression of behavioral sensitization: a critical review of preclinical studies. Psychopharmacology 151: 99-120.

van Erp AM, Miczek KA (2000). Aggressive behavior, increased accumbal dopamine, and decreased cortical serotonin in rats. $J$ Neurosci 20: $9320-9325$.

Varga V, Szekely AD, Csillag A, Sharp T, Hajos M (2001). Evidence for a role of GABA interneurones in the cortical modulation of midbrain 5-hydroxytryptamine neurones. Neuroscience 106: 783-792.

Volkow ND, Fowler JS (2000). Addiction, a disease of compulsion and drive: involvement of the orbitofrontal cortex (review) (86 refs). Cereb Cortex 10: 318-325.

Wang GJ, Volkow ND, Fowler JS, Cervany P, Hitzemann RJ, Pappas NR et al (1999). Regional brain metabolic activation during craving elicited by recall of previous drug experiences. Life Sci 64: 775-784.

Weiss F, Maldonado-Vlaar CS, Parsons LH, Kerr TM, Smith DL, Ben-Shahar O (2000). Control of cocaine-seeking behavior by drug-associated stimuli in rats: effects on recovery of extinguished operant-responding and extracellular dopamine levels in amygdala and nucleus accumbens. Proc Natl Acad Sci USA 97: 4321-4326.

Wexler BE, Gottschalk CH, Fulbright RK, Prohovnik I, Lacadie CM, Rounsaville BJ et al (2001). Functional magnetic resonance imaging of cocaine craving. Am J Psychiatry 158: 86-95.

Wilkinson LS, Humby T, Robbins TW, Everitt BJ (1995). Differential effects of forebrain 5-hydroxytryptamine depletions on pavlovian aversive conditioning to discrete and contextual stimuli in the rat. Eur J Neurosci 7: 2042-2052. 